\section{APLASTIC ANEMIA AND HEPATITIS C: MOLECULAR BIOLOGY EXONERATES ANOTHER SUSPECT}

Hibbs $J$, Frickhofen $N$, Rosenfeld S, Feinstone $S$, Kojima $S$, Bacigalupo A, Locasciulli A, et al. Aplastic anemia and viral hepatitis: non-A, non-B, non-C? JAMA 1992;267:2051-2054.

\section{ABSTRACT}

Objective.-To test the hypothesis that the rare, often fatal, syndrome of hepatitis-associated aplasia is associated with hepatitis $\mathrm{C}$ virus infection.

Design. - Case series.

Setting.- Tertiary referral centers in the United States, Japan, Italy, and Germany.

Patients. - Twenty-eight patients with onset of aplastic anemia within 90 days after seeking medical attention for jaundice, or having serum transaminase levels $150 \%$ or more of normal (hepatitis-associated aplasia patients) and three patients who developed aplastic anemia following liver transplantation for non-A, non-B, hepatitis.

Outcome Measures.-Presence of hepatitis $C$ in serum, bone marrow, and liver samples, detected by the polymerase chain reaction; antibody testing; and percentage of activated peripheral cytotoxic $T$ lymphocytes determined by immunophenotyping.

Results. - Hepatitis ribonucleic acid was present in the serum samples of $10(36 \%)$ patients with hepatitisassociated aplasia. However, hepatitic $\mathrm{C}$ virus viremia was associated with transfusions received after the onset of aplasia: seven (58\%) of 12 patients with hepatitis-associated aplasia who had received 21 or more units of blood products at the time of serum sampling were viremic, compared with only three (19\%) of 16 patients with hepatitis-associated aplasia who had received 20 or less units of blood products $(P<.05)$. Hepatitis $C$ virus was not found in blood and bone marrow samples of three National Institutes of Health case patients tested at the time of diagnosis. None of three livers from non-A, non-B hepatitis patients who developed aplastic anemia after liver transplantation contained hepatitis $C$ virus ribonucleic acid. Activated $\mathrm{CD8}^{+} \mathrm{T}$ lymphocytes were elevated three- to 20 -fold early in the course of hepatitisassociated aplasia.

Conclusions. - Our results implicate a novel, non-A, non-B, and non-C agent in both hepatitis-associated aplasia and fulminant hepatitis.

\section{COMMENTS}

Aplastic anemia is a rare but devastating complication of hepatitis. The association of hepatitis with aplastic

$31 / 8 / 44313$ anemia is interesting because it suggests metabolic commonalities between the bone marrow and the liver that have not been fully appreciated. The agent responsible for both the hepatitis and the aplastic anemia remains unknown but is presumed to be viral. Using the technique of reverse transcription combined with the polymerase chain reaction ( $\mathrm{RT}$-PCR) to detect hepatitis $\mathrm{C}$ virions, the authors of this paper add to the growing evidence that the hepatitis $\mathrm{C}$ virus is not responsible for the hepatitis or the subsequent aplastic anemia.

Hepatitis-associated aplastic anemia (H-AA) was first reported in the literature in $1955(1,2)$. As methods to detect and classify the different hepatitis viruses have improved, hepatitis $A$ virus (HAV) and HBV have been ruled out as etiological agents of $\mathrm{H}$-AA. The first case of $\mathrm{H}-\mathrm{AA}$ in which $\mathrm{HBV}$ and $\mathrm{HAV}$ were ruled out as causes was reported in 1981 (3). By 1983 a series of 16 patients with $\mathrm{H}-\mathrm{AA}$ had been examined for the presence of $\mathrm{HAV}$ and HBV (4). In 13 of these 16 cases, neither HAV nor HBV was present. The conclusion of this study was that some other hepatitis virus - non-A, non-B (NANB) was responsible for the $\mathrm{H}-\mathrm{AA}$ seen in the majority of these patients.

In 1990, complementary DNA (cDNA) cloning of hepatitis $\mathrm{C}$ virus (HCV) was reported (5), making possible the development of tests for the presence of serum antibodies to HCV (6). Shortly thereafter, the first experiments to test the hypothesis that HCV is the causative agent of $\mathrm{H}$-AA were reported. In a series of experiments, investigators examined 19 patients with H-AA, 38 patients with aplastic anemia from other known causes and 61 cases of aplastic anemia from entirely unknown causes (7). Those experiments revealed that $\mathrm{HCV}$ antibodies were present in only $15 \%$ of $\mathrm{H}$-AA cases, a percentage indistinguishable from that in cases of aplastic anemia resulting from other causes. The authors concluded that no association between $\mathrm{HCV}$ and $\mathrm{H}$-AA existed and suggested blood transfusions used in the treatment of aplastic anemia accounted for the uniform distribution of $\mathrm{HCV}$ antibodies among all groups of patients with aplastic anemia, regardless of the underlying causes. When evaluating this study two points should be kept in mind. First, with the firstgeneration assay used in this study, a considerable delay of up to several months occurs between infection with $\mathrm{HCV}$ and the development of $\mathrm{HCV}$ antibodies (8). Second, immunological abnormalities are seen in patients with H-AA that may interfere with an appropriate antibody response to $\mathrm{HCV}$ infection (9). Therefore the absence of antibodies to $\mathrm{HCV}$ appears to be an insensitive indicator for ruling out recent infection with $\mathrm{HCV}$ in patients with $\mathrm{H}-\mathrm{AA}$. 
The development of RT-PCR has allowed the direct measurement of hepatitis $\mathrm{C}$ virions in serum and in tissues (10). In brief, the virus is pelleted from serum, plasma or tissue homogenate; the viral capsid is solubilized; and the viral RNA is released into solution. The RNA is reverse transcribed in vitro, and then, with a pair of DNA primers specific for the viral cDNA, the viral cDNA is simplified sufficiently for detection on an ethidium bromide-stained gel. The specificity of RT-PCR can be enhanced with the addition of nested primers, which are a second set of DNA primers specific for the viral genome at an internal site distinct from the first set of primers but which are still contained within the simplified DNA. Most laboratories that use this method with nested primers specific for the $5^{\prime}$ end of the HCV genome report a sensitivity of $90 \%$ to $100 \%$ (11).

The authors of this paper present the analysis of 28 patients with $\mathrm{H}-\mathrm{AA}$, the largest series to date, using RT-PCR to detect HCV in the serum and tissues of the patients. Their primary hypothesis was that hepatitis $\mathrm{C}$ is responsible for H-AA. Initially, the authors analyzed serum and bone marrow samples from three patients with $\mathrm{H}-\mathrm{AA}$ who were referred to the National Institutes of Health. Using RT-PCR, the authors were unable to detect HCV RNA in the serum or the bone marrow of these three patients. Furthermore, none of these patients had antibodies to $\mathrm{HCV}$ as determined by the second-generation ELISA. After obtaining these negative results, the authors analyzed samples from other cases of H-AA at the National Institutes of Health and samples from cases of H-AA in Germany, Japan and Italy. In all, 28 cases of H-AA were analyzed for the presence of HCV. Overall, only 10 of the 28 patients had HCV RNA detectable in serum; an additional three patients had a positive antibody test but a negative RT-PCR test. When the cases were stratified by the number of transfusions received before the samples for $\mathrm{HCV}$ testing were obtained, the presence of $\mathrm{HCV}$ markers appeared to correlate with the number of transfusions given to treat the aplastic anemia. Of the 28 patients, 9 received fewer than five units of blood products, and none was positive for HCV antibody or HCV RNA. Seven patients received between 8 and 20 units of blood products before testing; three of these seven patients were positive by RT-PCR, and an additional two were positive for HCV antibody. Among the six patients who had received between 21 and 46 units, three were positive by RT-PCR and an additional two were positive for HCV antibody. Six patients received 74 or more units of blood products before testing, and four of the six were positive by RT-PCR. On the basis of these data, the authors concluded that in the majority of patients with H-AA, HCV cannot be implicated as the causative agent; instead, HCV infection is acquired as a consequence of the treatment of aplastic anemia.

Almost incidentally, the authors included data on peripheral lymphocytes in their original three patients. They detected an increase in $\mathrm{CD8}^{+}, \mathrm{DR}^{+}$peripheral lymphocytes expressed as a percentage of total lymphocytes, and they concluded that this increase in activated
$\mathrm{CD}^{+}$lymphocytes was consistent with a recent viral infection. An earlier report indicated that the total number of peripheral $\mathrm{T}$ lymphocytes is diminished in H-AA (9). Therefore it is difficult to draw any conclusions from the presented data because the authors do not express the data as an absolute number of $\mathrm{CD}^{+}, \mathrm{DR}^{+}$lymphocytes and because the sample size is so small. Furthermore, an increase in $\mathrm{CD} 8^{+}$lymphocytes, although consistent with recent viral infection, can be seen in many other nonviral conditions and does not necessarily support a viral cause for the H-AA cases being studied.

The authors used RT-PCR to examine the largest assembled group of H-AA patients to date. Experiments presented in this paper appear with appropriate controls, and the main conclusions reached are supported by the data. Most convincing is the analysis of the nine patients who received fewer than five units of blood products. None of these patients was positive for HCV. RT-PCR has proved to be a very sensitive method of detecting HCV viremia and is presently the only method for detecting viremia short of inoculating uninfected primates with the serum in question. Of note, the group that examined 19 patients with H-AA and 99 patients with aplasia of other causes has reexamined their samples using RT-PCR (12). They report, in abstract form, that only 4 of the 19 samples from H-AA patients were positive for $\mathrm{HCV}$ RNA and that this rate of hepatitis $\mathrm{C}$ viremia was no different from that in the group with aplastic anemia of other causes. The present study, which uses RT-PCR to detect HCV RNA, represents an advance in our understanding of H-AA and indicates that we will have to search further for a convincing culprit. We may even have to reexamine some of our present assumptions about H-AA. The causative agent of H-AA may not be a hepatotrophic virus or even a virus at all. Perhaps it is time we reconsider toxic injury or a nonhepatotrophic virus as a suspect in H-AA.

Dale BACHWICH, M.D.
JULES DIENSTAG, M.D.
Massachusetts General Hospital
Boston, Massachusetts 02114

\section{REFERENCES}

1. Lorenz E, Quaiser K. Panmyelopathie nach hepatitis epidemica. Wien Med Wochenschr 1955;105:19.

2. Hagler L, Pastore RA, Bergin JJ. Aplastic anemia following viral hepatitis: report of two fatal cases and literature review. Medicine 1975;54:139-164.

3. Perillo RP, Pohl DA, Roodman ST, Tsai CC. Acute non-A, non-B hepatitis with serum sickness-like syndrome and aplastic anemia. JAMA 1981;245:494-496.

4. Zeldis JR, Dienstag JL, Gale RP. Aplastic anemia and non-A, non-B hepatitis. Am J Med 1983;74:64-68.

5. Choo QL, Kuo G, Weiner A, Overby LR, Bradley DW, Houghton M. Isolation of a cDNA clone derived from a blood-borne non-A, non-B viral hepatitis genome. Science 1989;244:359-362.

6. Kuo G, Choo QL, Alter HJ, Gitnick GL, Redeker AG, Purcell RH, Miyamura $T$, et al. An assay for circulating antibodies to a major etiologic virus of human non-A, non-B hepatitis. Science 1989; 244:362-364 
7. Pol S, Driss F, Devergie A, Brechot C, Berthelot P, Gluckman B Is hepatitis $\mathrm{C}$ virus involved in hepatitis-associated aplastic anemia? Ann Intern Med 1990;113:6:435-437.

8. Alter L, Purcell RH, Shih JW, Melopolder JC, Houghton M, Choo $\mathrm{QL}$, Kuo G. Detection of antibody to hepatitis $\mathrm{C}$ virus in prospectively followed transfusion recipients with acute and chronic non-A, non-B hepatitis. N Engl J Med 1989;321:14941500 .

9. Foon KA, Mitsuyasu RT, Schroff RW, McIntyre RE, Champlin R, Gale RP. Immunologic defects in young male patients with hepatitis-associated aplastic anemia. Ann Intern Med 1984;100: $5: 657-662$

10. Weiner AJ, Kuo G, Bradley DW, Bonino F, Saracco G, Lee C, Rosenblatt $J$, et al. Detection of hepatitis $C$ viral sequences in non-A, non-B hepatitis. Lancet 1990;335:1-3.

11. Inchauspe $G$, Abe K, Zebedee S, Nasoff M, Prince AM. Use of conserved sequences from hepatitis $\mathrm{C}$ virus for the detection of viral RNA in infected sera by polymerase chain reaction. HEPA TOLOGY 1991;14:4:595-600.

12. Pol S, Thiers V, Driss F, Devergie A, Berthelot P, Brechot C Gluckman E. HCV plays no role in hepatitis-associated aplastic anemia |Abstract]. HEPATOLOGY 1992;16:2:71A.

\section{PUSH ME-PULL YOU: THE CHALLENGE OF ENDOCYTIC SORTING}

Goltz JS, Wolkoff AW, Novikoff PM, Stockert RJ, Satir $\boldsymbol{P}$. A role for microtubules in sorting endocytic vesicles in rat hepatocytes. Proc Natl Acad Sci USA 1992;89:7026-7030.

\section{ABSTRACT}

The vectorial nature of hepatocyte receptor-mediated endocytosis (RME) and its susceptibility to cytoskeletal disruptors has suggested that a polarized network of microtubules plays a vital role in directed movement during sorting. Using as markers a wellknown ligand, asialoorosomucoid, and its receptor, we have isolated endocytic vesicles that bind directly to and interact with stabilized endogenous hepatocyte microtubules at specific times during a synchronous, experimentally initiated, single wave of RME. Both ligand- and receptor-containing vesicles copelleted with microtubules in the absence of ATP but did not pellet under similar conditions when microtubules were not polymerized. When $5 \mathrm{mM}$ ATP was added to preparations of microtubule-bound vesicles, ligandcontaining vesicles were released into the supernatant, while receptor-containing vesicles remained immobilized on the microtubules. Release of ligandcontaining vesicles from microtubules was prevented by monensin treatment during the endocytic wave. Several proteins, including the microtubule motor protein cytoplasmic dynein, were present in these preparations and were released from microtubule pellets by ATP addition concomitantly with ligand. These results suggest that receptor domains within the endosome can be immobilized by attachment to microtubules so that, following monensin-sensitive dissociation of ligand from receptor, ligand-containing vesicles can be pulled along microtubules away from the receptor domains by a motor molecule, such as cytoplasmic dynein, thereby delineating sorting.

\section{COMMENTS}

The binding of extracellular proteins (and other macromolecules) to plasma membrane receptors enables eukaryotic cells to internalize selected proteins for their specific uses. This process is accomplished through receptor-mediated endocytosis (RME), whereby the binding of an exogenous protein to a receptor initiates receptor clustering within localized regions of the plasma membrane, which are usually demarcated by the binding of the soluble cytoplasmic protein clathrin to the underside of the membrane. The plasma membrane then invaginates and pinches off, generating a membrane-bounded, clathrin-coated vesicle. The clathrin then dissociates from the vesicle, generating an endocytic vesicle or "early endosome"; within its lumen is the desired protein ligand, and the vesicle membrane contains the receptor protein. In this manner, cells can import entire proteins from the extracellular environment and still maintain the segregation of exogenous proteins from the cytoplasmic space. The ability to recognize and internalize macromolecules is an essential part of intercellular communication and coordination in multicellular organisms.

Once internalized, the endocytosed macromolecule must be directed toward its final destination. In hepatocytes uptake and sorting of plasma-derived proteins can be divided into roughly three pathways (1): toward lysosomes for degradation (e.g., asialoglycoproteins, lipoproteins, epithelial growth factor and its receptor); toward the biliary pole of the hepatocyte for direct excretion into bile (IgA and its receptor); and toward intracellular regulatory sites (some hormones and growth factors). However, this process must be accomplished while maintaining the integrity of the cell exterior. In hepatocytes the equivalent of the entire cell surface is endocytosed several times each hour. Accordingly, the endocytosed membrane (and in many cases the receptors) are recycled back to the cell surface.

The first station in endocytic sorting is the dissociation of bound protein from the receptor. Endocytic vesicles enter into the early endosomal compartment, an organelle of considerable structural complexity exhibiting irregularly shaped spherical vesicles attached to extended tubular structures that have interconnections. Acidification of the lumen of these endocytic structures through the action of proton pumps is a basic mechanism for dissociating ligand from the receptor because many proteins (such as asialoglycoproteins) bind strongly to their receptors at neutral $\mathrm{pH}$ outside the cell but dissociate at the low $\mathrm{pH}$ achieved within endosomes. The receptors and membrane to be recycled are then segregated from ligand-containing vesicles ("late endosomes"); these vesicles include large transport vesicles up to $0.5 \mu \mathrm{m}$ in diameter and vacuoles with contained vesicles (multivesicular bodies), which then move toward their final destination.

The architectural complexity of the endosomal compartment suggests a role for the cytoskeleton, in particular microtubules, which now has been well documented (2). Microtubules are tubular polymers in dynamic equilibrium with dimeric tubulin, a soluble cytoplasmic protein composed of $\alpha$-polypeptide and $\beta$-polypeptide subunits. The asymmetry in tubulin generates asymmetrical polarized microtubules, in which the $\alpha$-oriented end, designated (+), is predominantly oriented toward the cell periphery and the 